\title{
Dust storm frequency after the 1999 drought in the Sistan region, Iran
}

\author{
Abbas Miri ${ }^{1, *}$, Alireza Moghaddamnia ${ }^{1}$, Ahmad Pahlavanravi ${ }^{1}$, Naser Panjehkeh ${ }^{2}$ \\ ${ }^{1}$ Department of Range and Watershed Management, Faculty of Natural Resources, and \\ ${ }^{2}$ Department of Plant Protection, Faculty of Agriculture, University of Zabol, Zabol, Iran
}

\begin{abstract}
Sustained drought and reduced precipitation in the Sistan region, Iran, has dried the Hamoun Lake and local vegetation, significantly reducing ground cover. These conditions have permitted strong wind erosion on already susceptible land. Analysis of data collected from the synoptic station in Zabol from 1999 to 2004 revealed that after 1999 the total number of dust storm events (DST) increased considerably. Accordingly, the number of hours of dusty air and the Dust Storm Index (DSI) have increased and horizontal visibility has decreased. Increasing DST and DSI values and decreasing horizontal visibility are indicators of dustiness in the region. The highest DST and DSI values - 74 and $149 \mathrm{~d}$, respectively - were observed in 2001. The indexes were higher in July and August every year. Additionally, a relationship was observed between increasing DST and DSI, drought occurrence and wind speed. Drought occurrence, an increase in wind speed and Lake Hamoun dryness have severely intensified dustiness in the region.
\end{abstract}

KEY WORDS: Dust storm $\cdot$ Dust storm total $\cdot$ Dust Storm Index $\cdot$ Horizontal visibility $\cdot$ Sistan region

\section{INTRODUCTION}

Dust storms are not only weather phenomena, but also geomorphic processes around which much research has been undertaken in the context of land degradation or desertification (Zhang 1984, Pye \& Tsoar 1991, Tucker et al. 1991, Wang et al. 1996, Xia \& Yang 1996, Fang et al. 1997, Shi et al. 2000, Wang 2000, Reynolds \& Stafford-Smith 2002). Their occurrence, development and transport are related to the dynamics of weather and climate patterns at a range of different scales (Chang et al. 1996, Qiu et al. 2001, Tao et al. 2004). The formation of dust storms depends on 3 conditions (Xia \& Yang 1996, Wang et al. 2001): (1) strong winds (the driving force for sanddust erosion and transport); (2) susceptible surface material to wind erosion (the material supply condition); and (3) unstable atmospheric conditions (local thermodynamic and also neutral conditions are typical for wind erosion). Shi \& Zhao (2003), presenting a forecast system of sand and dust events, note that soil type, vegetation characteristics, land-use type and topsoil water content are important parameters for modelling atmospheric transport of sand. Many factors, such as vegetation (Wiggs et al. 1995, Lancaster 1998, Zhang et al. 2004), soil crust (Li et al. 2001, Eldridge \& Leys 2003, Hupy 2004), topsoil moisture (Liu et al. 2003), aerodynamic roughness of cultivated topsoil (Zhang et al. 2002), soil texture (Zobeck 1991, Dong \& Li 1998) and organic matter (Chepil 1954, Zobeck 1991, Li et al. 2001, Eldridge \& Leys 2003), can control soil erosion.

Broad-scale wind erosion can be approximated using meteorological data that reports the frequency of occurrence of dust events (dust storms and local dust events) weighed according to their intensity as a Dust Storm Index (DSI; Squires 1995). Spatial and temporal changes in wind erosion rates are measured by using the DSI, and the impacts of land use are approximated by comparing measured DSI values with the rates predicted by a wind erosion model (Ew model) (Burgess et al. 1989, McTainsh et al. 1990). 
To the best of our knowledge, no report has as yet been published on the dust storms in Iran, although a methodology has been developed by the Forests, Rangelands and Watershed Organization of Iran, which is being applied to gather data countrywide (Tac Sabz 2002).

\section{STUDY AREA}

The Sistan region in the southeast of Iran (Fig. 1) has very varied climatic conditions. Iran is situated in the desert belt of the Northern Hemisphere, and a large part of the internal lands and southern border of Iran has a dry and semidry climate. The annual precipitation in the lower Sistan Basin is about $50 \mathrm{~mm}$ (WAPCOS 1975). The Helmand River plays a major role in the Sistan region by draining the snowmelt waters from the mountains of the southern Hindu Kush.

Based on satellite image analysis, Vekerdy et al. (2006) described 4 different flow periods that can be discerned over the last $20 \mathrm{yr}$ in Lake Hamoun, including a low-water period from 1985 to 1988, a high-water period from 1989 to 1993, a medium-water period from 1994 to 1999, and a dry period from 2000 to 2004 .

The Sistan region is subject to severe winds (the 120 d winds, also known as Levar) that set in at the end of May to the middle of June, and blow at wind speeds occasionally reaching $30 \mathrm{~m} \mathrm{~s}^{-1}$ for about 3 mo. Levar always blows from the northeast (McMahon 1906), and is thought to be modulated by the intense solar heating of the South Asia landmass, since it is only a summer phenomenon. The physical mecha-

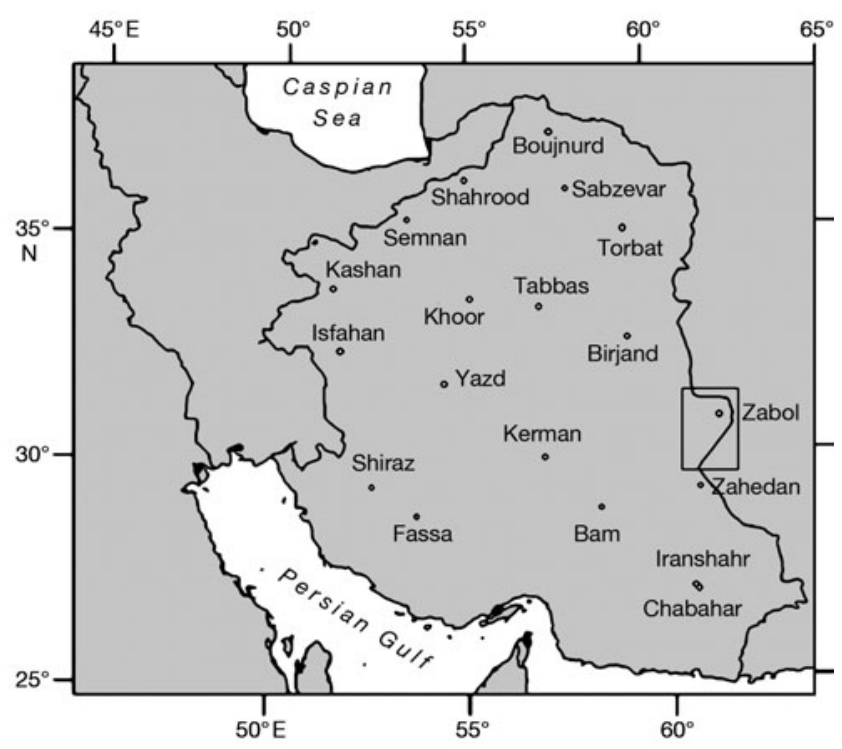

Fig. 1. Sistan region, southeast Iran nism that leads to such an atmospheric system has not been satisfactorily explained; however, it has been attributed to the formation of an intense shallow low pressure system over South Asia due to a strong positive turbulent sensible heat flux (Hossenzadeh 1997). Other studies suggest that the Levar might also be a limb of the return flow of the Indian Monsoon circulation (Hahn \& Manabe 1975). Another possibility could be local heating of the Sistan Basin, leading to a plains-basin thermally generated flow (De Wekker et al. 1998). It is also possible that all forcings interact. After the 1999 drought, owing to land-use change (abandonment of agricultural land) and the drying up of Hamoun Lake (located in the north of the region; Fig. 2), the frequency and severity of dust storms have increased significantly. At present, a wide portion of the region is subject to soil erosion that, in turn, is a source of dust storms. Fig. 3 shows photos of Zabol city before and after the dust storm occurrence of 1999.

\section{DATA SETS AND METHODOLOGY}

Data including dust storm onset and horizontal visibility were collected from the Zabol synoptic station. Data were recorded every $3 \mathrm{~h}$ during day and night. According to the WMO, a dust storm is defined as a windy day in which the wind speed exceeds $15 \mathrm{~m} \mathrm{~s}^{-1}$ and the visibility is reduced to less than $1000 \mathrm{~m}$ (codes 30 to 35 , Table 1). We measured the total number of dust storm events (DST) as the total number of days (monthly and annually) which met the WMO dust storm definition.

Dust entrainment events have recently been combined into a DSI (Squires 1995, McTainsh 1998, Burgess et al. 1989). The DSI provides a more sensitive measure of wind erosion than dust storm frequencies because it measures the composite effect of a range of dust event type, weighed according to its intensity. The DSI is defined as:

$$
\mathrm{DSI}=5 \mathrm{SD}+\mathrm{MD}+\mathrm{LDE} / 20
$$

(see Table 2 for definitions).

Visibility as a standard meteorological parameter is regularly measured at synoptic meteorological stations worldwide. It is determined mostly by the light extinction of aerosol particles. The reduction of horizontal visibility might occur because of atmospheric phenomena such as dust, fog, heavy rainfall, etc. The changes within temporary wind speed can be shown by horizontal visibility. On the other hand, horizontal visibility depends on wind velocity. Monthly visibility is on average $\leq 1$ to $5 \mathrm{~km}$ in dusty storm conditions in the Sistan region. 

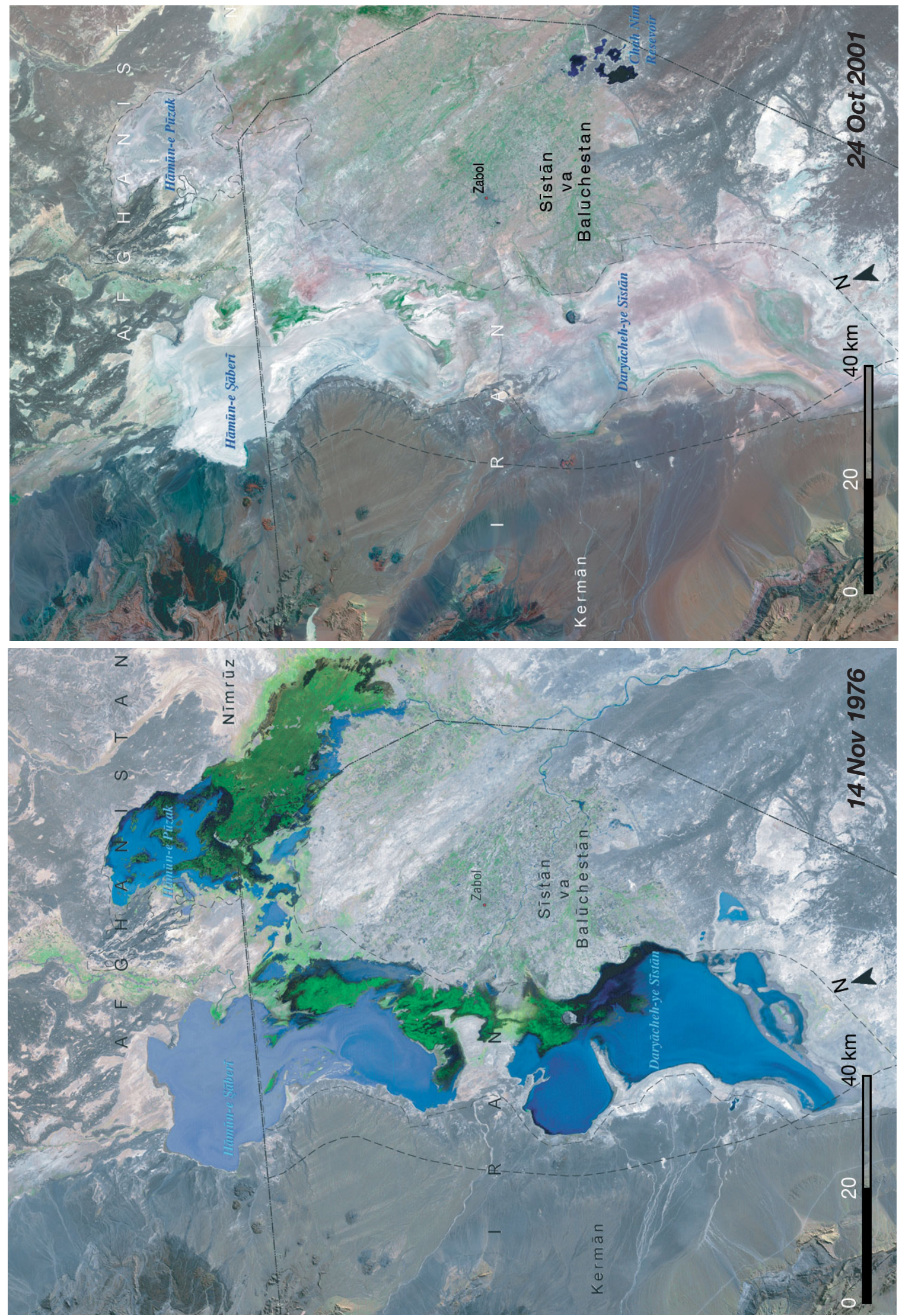

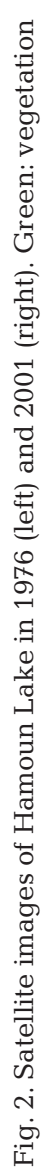




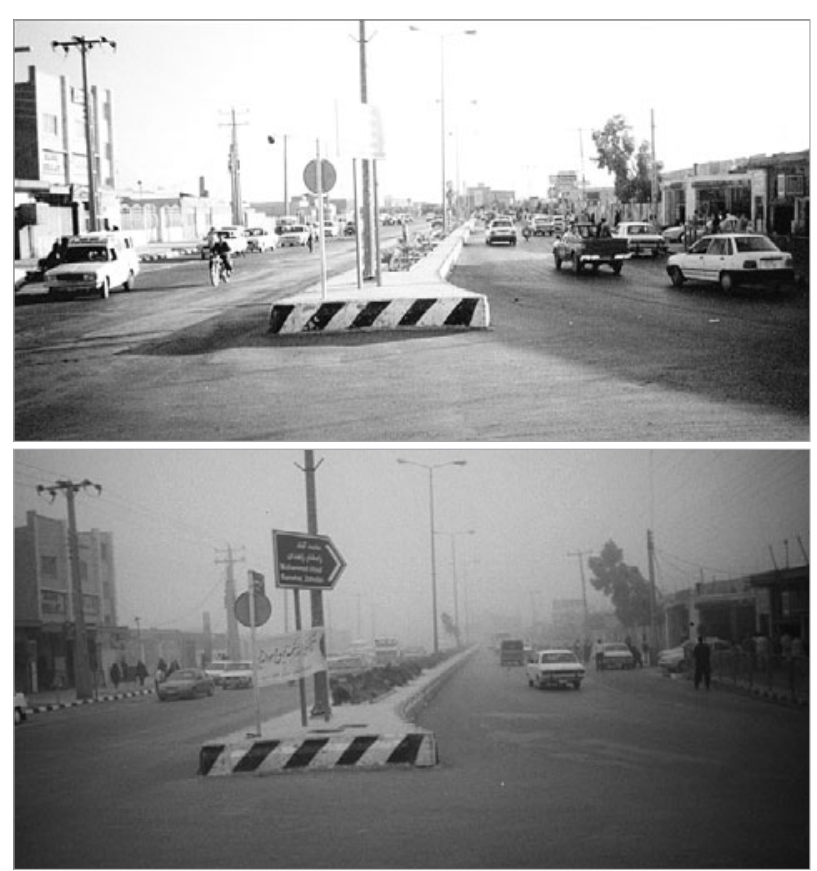

Fig. 3. City of Zabol in the Sistan region on a clear day (top) and a dusty day (bottom)

Table 1. Phenomena arising from dust storms according to the standard codes defined by the WMO. LDE: local dust event (total suspended particulate matter $<150 \mu \mathrm{g} \mathrm{m}^{-3} \mathrm{~h}^{-1}$ ); MD: moderate dust storm (visibility $<1000 \mathrm{~m}$ ); SD: severe dust storm (visibility <200 m); after Squires (2001)

Type Code Description

LDE 07 Dust or sand raised by wind at or near the station at the time of observation, but no well developed dust whirl(s) or sand whirl(s), and no dust storm or sandstorm seen

08 Well-developed dust whirl(s) or sand whirl(s) seen at or near the station during the preceding hour or at the time of observation, but no dust storm or sandstorm

MD 09 Dust storm or sandstorm within sight at the time of observation, or at the station during the preceding hour

30 Slight or moderate dust storm or sandstormhas decreased during the preceding hour

31 Slight or moderate dust storm or sandstormno appreciable change during the preceding hour

32 Slight or moderate dust storm or sandstormhas begun or has increased during the preceding hour

SDE 33 Severe dust storm or sandstorm - has decreased during the preceding hour

34 Severe dust storm or sandstorm - no appreciable change during the preceding hour

35 Severe dust storm or sandstorm - has begun or has increased during the preceding hour

\section{RESULTS}

\subsection{Variation in DST}

Results show that DST has increased in the study region since 1999. The average annual number of dust storm events increased from 10 d during 1990-1998 (before the drought) to $54 \mathrm{~d}$ during 1999-2004 (after the drought). The frequency of dust storms also increased 5-fold after 1999 in the region. The monthly variations in DST are shown in Fig. 4.

The dustiest year in the study period was 2001, when DST was 74 d. DST values in 1999, 2000, 2002, 2003 and 2004 were 23, 55, 54, 69 and 46 d, respectively, indicating that after the drought an increase in the number of dusty days was observed. Before the drought, SDEs happened rarely, but after 1999 the frequency and severity of dust storms increased.

As seen in Fig. 4, most of the months during 1999-2004 exhibited DST conditions, even in autumn and winter, although dust storms usually occur more often spring and summer. June and July, with 12 and 11 dusty days, respectively, had the worst wind speed and visibility conditions.

\subsection{Variation in DSI}

To estimate dusty conditions and determine susceptible regions to wind erosion, Eq. (1) was applied to all dusty stormy days with different horizontal visibility. The value of all days were converted to the dusty days with a horizontal visibility of $<1000 \mathrm{~m}$. All dusty days were included in the DSI calculation.

The monthly variations in DSI are shown in Fig. 4. The annual variations in DSI are shown in Fig. 5. The DSI increased sharply from 1999 to 2001, with a peak of $149 \mathrm{~d}$ in 2001. The average DSI was $13 \mathrm{~d}$ during 1990-1998, while it was 88 d during 19992004.

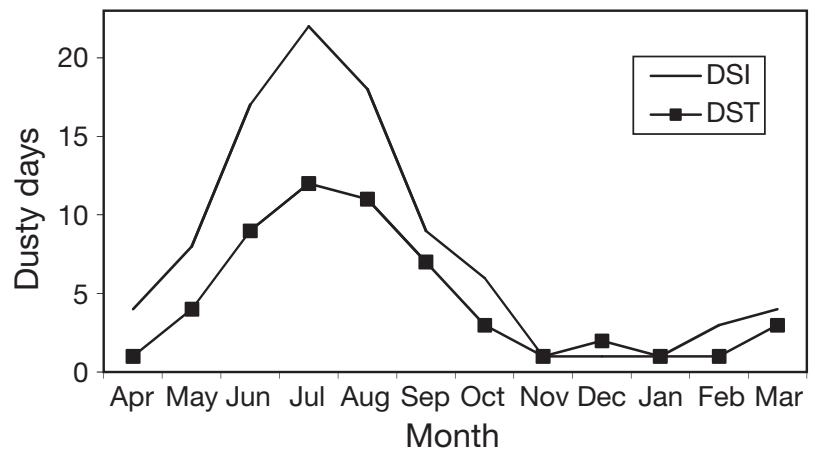

Fig. 4. Monthly average dust storm total (DST) and Dust Storm Index (DSI) in the Sistan region during 1999-2004 


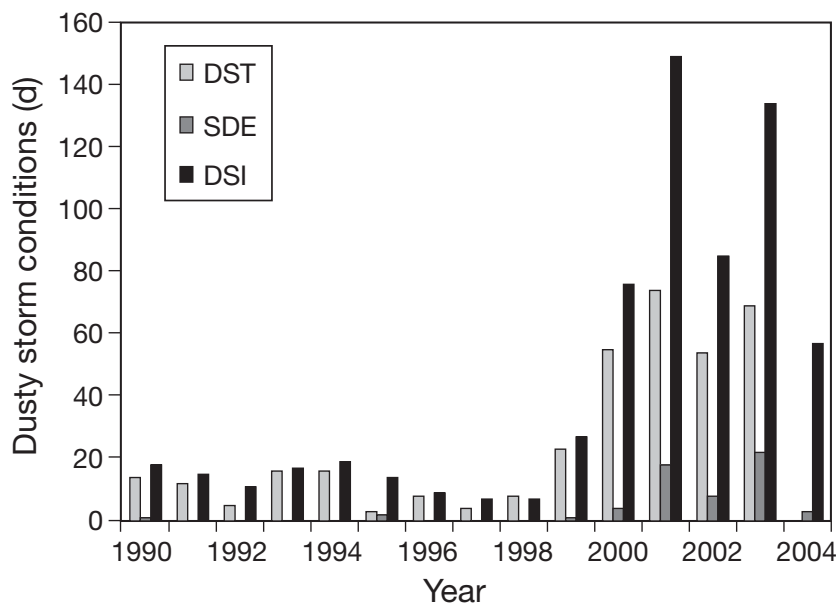

Fig. 5. Changes in dust storm total (DST), severe dust storms (SDE) and Dust Storm Index (DSI) during 1990-2004 in the Sistan region

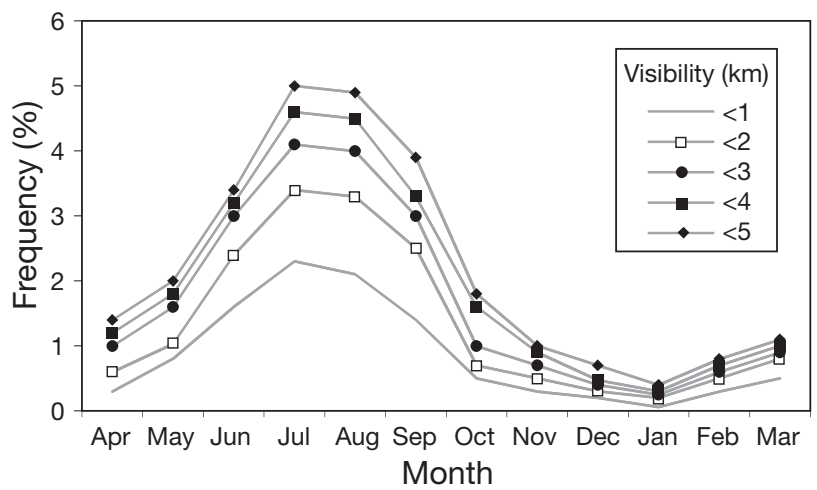

Fig. 6. Monthly average horizontal visibility from $\leq 1$ to $5 \mathrm{~km}$ during storm occurrence in the Sistan region during 1999-2004

\subsection{Variation in visibility}

As shown in Fig. 6, the frequency of low visibility (1 to $5 \mathrm{~km}$ ) was highest in summer. Fig. 7 shows the frequency of horizontal visibility during 1999-2004.

\subsection{Duration of dust storms}

The mean duration of dust storms was 60 and $341 \mathrm{~h}$ during 1990-1998 and 1999-2004, respectively (Fig. 8). The maximum duration was $531 \mathrm{~h}$ in 2001 and the minimum duration was $6 \mathrm{~h}$ in 1991.

\subsection{Relationship between rainfall and DST and DSI}

Rainfall in the Sistan region decreased significantly after the 1999 drought, from an average of $81 \mathrm{~mm}$

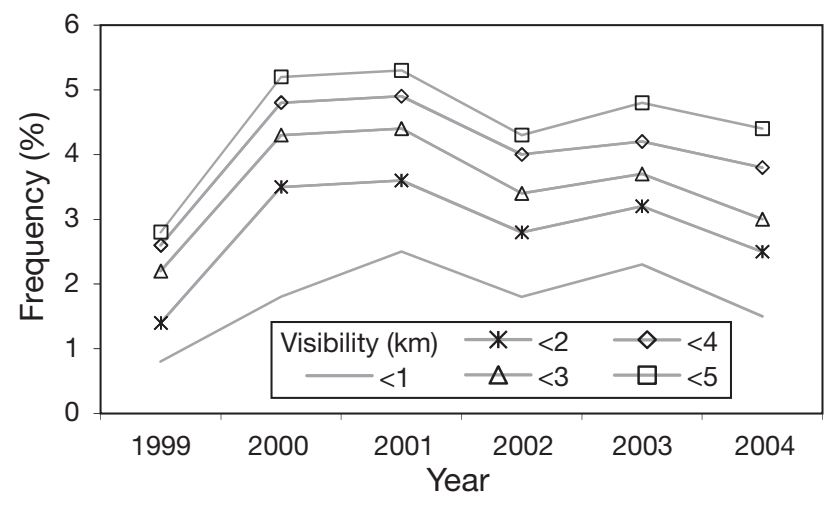

Fig. 7. Frequency of horizontal visibility $\leq 1$ and $5 \mathrm{~km}$ during dust storm occurrence in the Sistan region during 1999-2004

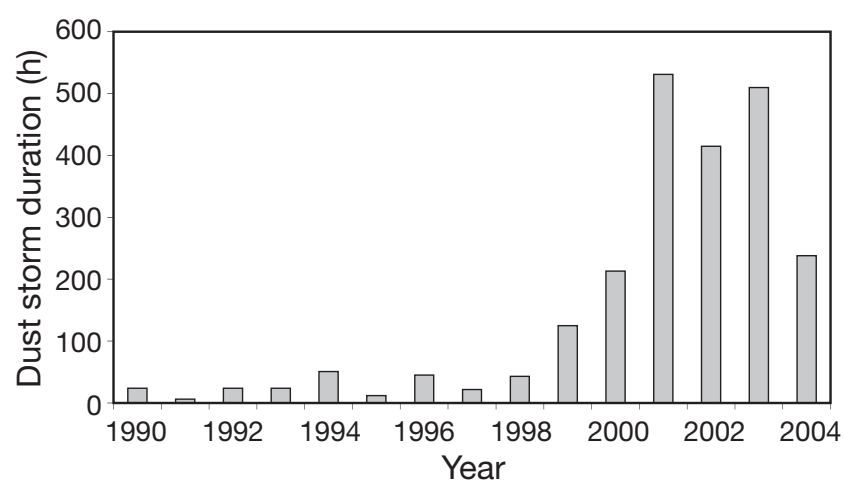

Fig. 8. Changes in the total annual duration of dust events in the Sistan region during 1990-2004

during 1990-1998 to $40 \mathrm{~mm}$ during 1999-2004. The annual rainfall in 2000 was $7 \mathrm{~mm}$. The reduction in rainfall caused sparseness in vegetation, reduction of superficial soil moisture and the drying up of Hamoun Lake, followed by accelerated soil erosion and increased transport of soil particles. The values of DST and DSI were very high between June and October (months without any rainfall) and also after the 1999 drought (Figs. 9 \& 10).

\subsection{Relationship between wind speed, and DST and DSI}

Sparse vegetation, bare soil and the high temperature difference between the Hindu Kush Mountains and the Sistan region after the 1999 drought contributed to a major increase in wind speed in the Sistan region over the $10 \mathrm{yr}$ period from the early 1990s. The high wind speed caused accelerated soil erosion and atmospheric transport, and an increase in both DST and DSI (Figs. 11 \& 12). 


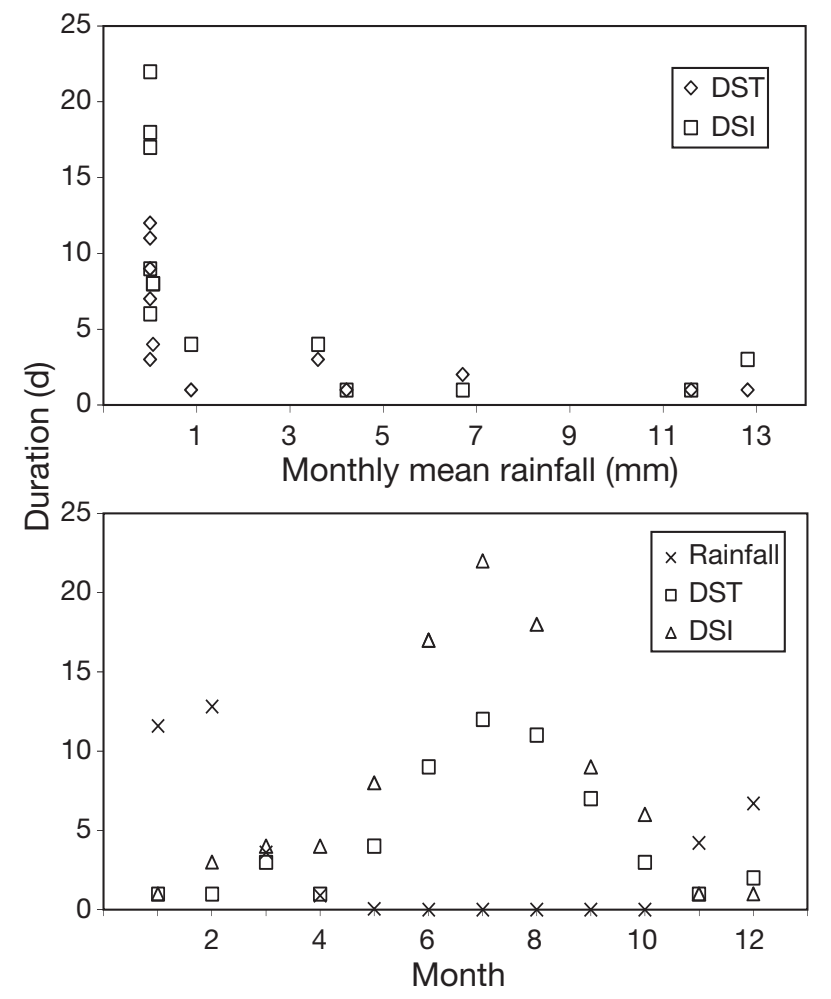

Fig. 9. Relationship between monthly rainfall and dust storm total (DST) and Dust Storm Index (DSI) in the Sistan region during 1990-2004

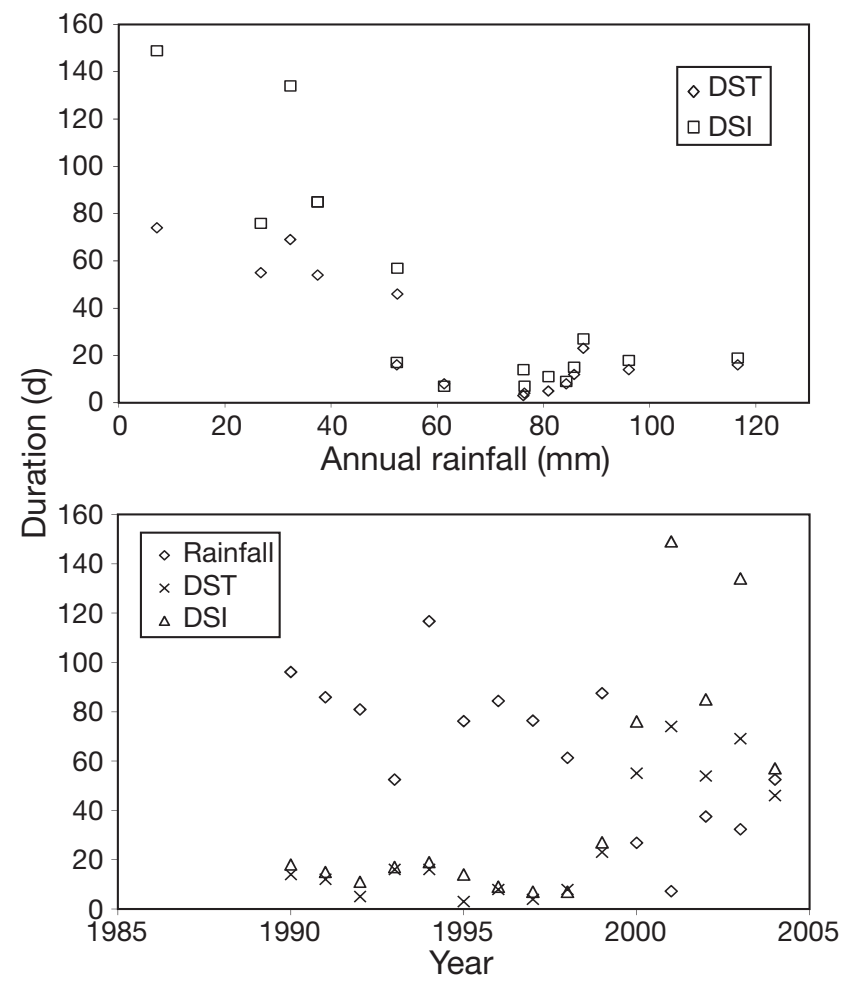

Fig. 10. Relationship between annual rainfall and dust storm total (DST) and Dust Storm Index (DSI) in the Sistan region during 1990-2004

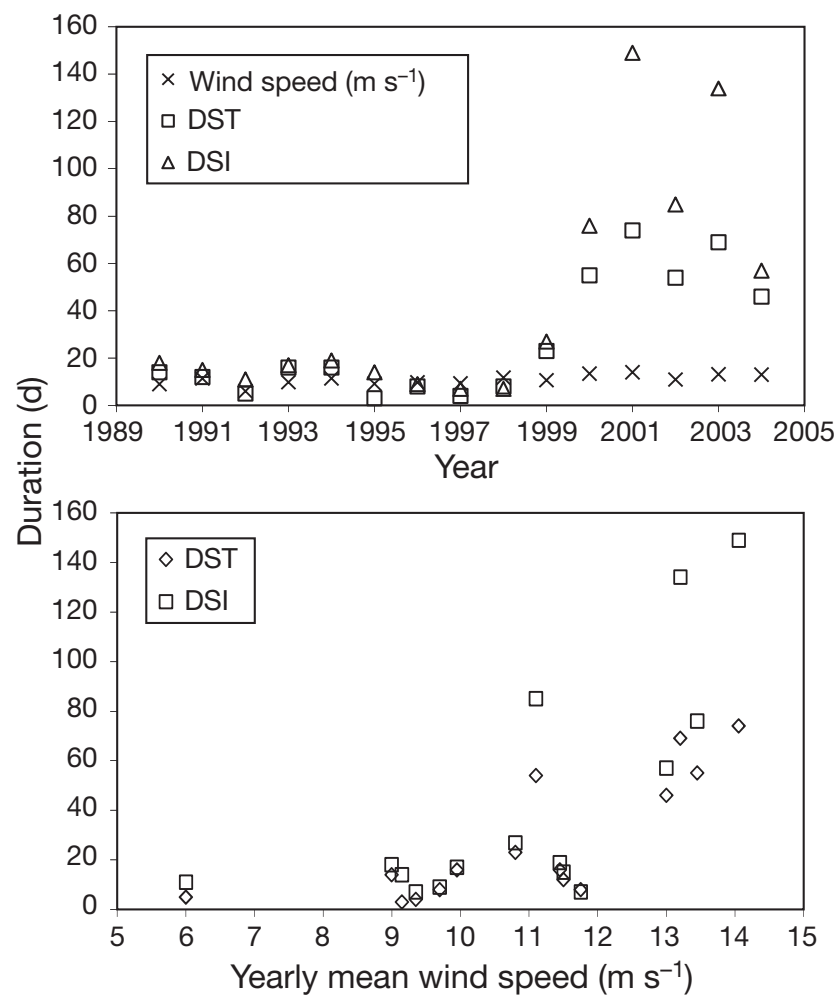

Fig. 11. Relationship between annual mean wind speed and dust storm total (DST) and Dust Storm Index (DSI) in the Sistan region during 1990-2004

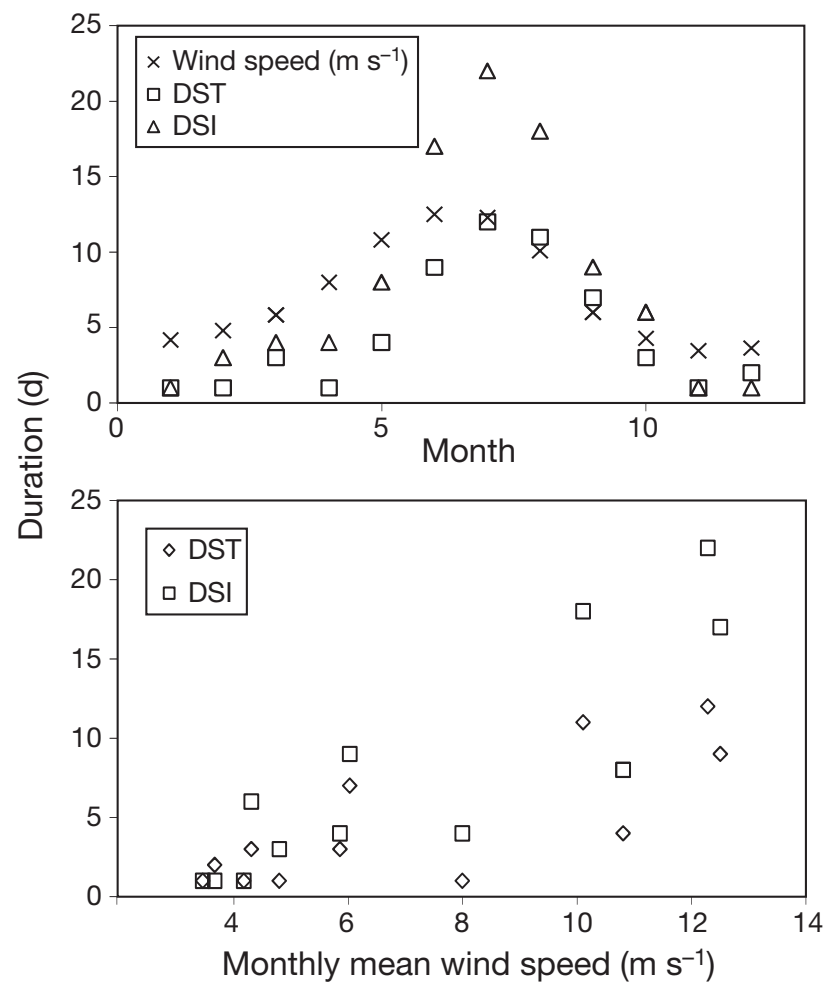

Fig. 12. Relationship between monthly mean wind speed and dust storm total (DST) and Dust Storm Index (DSI) in the Sistan region during 1990-2004 


\section{DISCUSSION}

Although the Sistan Basin has always been one of the crucial hubs of wind erosion in Iran, the incidence of wind erosion has increased in recent years. The indices DST and DSI increased dramatically from 10 and $13 \mathrm{~d}$ during $1990-1998$ to 54 and $88 \mathrm{~d}$ during 1999-2004, respectively. This shift is associated with an increase in wind speed, rainfall reduction, drying of Hamoun Lake and drought occurrence. In the months of June, July, August and September, DST and DSI reached their maximum, while the horizontal visibility was at its minimum. In conclusion, the increase in DST and DSI as well as the reduction in horizontal visibility after the 1999 drought in the Sistan region are indicators of an increase in wind erosion and dustiness. Our results indicate that drought occurrence is the most important factor in the observed increase in dustiness.

Based on the research being conducted in other areas of Iran, the fixation of sand dunes and creation of a green belt using native plants such as Tamarix spp., Atriplex spp., Haloxylon spp., Stipagrostis spp., Citrullus colocynthis, Sasola spp. and Eucalyptus spp., and other practices such as farmland management, modern farming approaches and soil conservation programmes are major approaches to the control of dust storms and wind erosion (Zehtabian et al. 2006, Safarnejad 2005, Bahrami \& Jariyani 2003, Ekhtesasi 2003). As Hamoun Lake is the original source area of dust storms in the study region (Iranmanesh et al. 2005), creation of a green belt along the shores of the lake is necessary to control the dust storms.

\section{LITERATURE CITED}

Bahrami A, Jariyani M (2003) Haloxylon and its function in wind erosion control in Iran center. Proc Haloxylon conference, Rahe Sobhan Press, Kerman, Iran, p 64-65

Burgess RC, McTainsh GH, Pitblado JR (1989) An index of wind erosion in Australia. Aust Geogr Stud 27:98-110

Chang YS, Arndt RL, Carmichael GR (1996) Mineral basecation deposition in Asia. Atmos Environ 30:2417-2427

Chepil WS (1954) Factors that influence clod structure and erodibility of soil by wind: III. Calcium carbonate and decomposed organic material. Soil Sci 77:473-480

> De Wekker SFJ, Zhong S, Fast JD, Whiteman CD (1998) A numerical study of the thermally driven plain-to-basin wind over idealized basin topographies. J Appl Meteorol 37:606-622

Dong ZB, Li ZS (1998) Wind erodibility of aeolian sand as influenced by grain-size parameters. J Soil Water Conserv 4:1-12 (in Chinese)

Ekhtesasi MR (2003) Determination of the minimum amount of concentration of Haloxylon to create breaking wind and wind erosion control in Iran center. Proc Haloxylon conference, Rahe Sobhan Press, Kerman, Iran, p 2-3

Eldridge DJ, Leys JF (2003) Exploring some relationships between biological soil crusts, soil aggregation and wind erosion. J Arid Environ 53:457-466

Fang ZY, Zhu FK, Jiang JX (1997) A study of sandstorms in China. Publishing House for Meteorology, Beijing (in Chinese)

- Hahn DG, Manabe S (1975) The role of mountains in the South Asian Monsoon circulation. J Atmos Sci 32:1515-1541

Hossenzadeh SR (1997) One hundred and twenty days winds of Sistan. Iran J Res Geogr 46:103-127

Hupy JP (2004) Influence of vegetation cover and crust type on wind-blown sediment in a semi-arid climate. J Arid Environ 58:167-179

Iranmanesh F, Arabkhedri M, Akram M (2005) Investigation of dust origins and characteristics of their spreading in Sistan's storms, Iran, using image processing. J Res Constr Nat Res 67:25-33

> Lancaster NA (1998) Influence of vegetation cover on sand transport by wind: field studies at Owens Lake, California. Earth Surf Process Landf 23:69-82

Li XR, Jia YK, Long LQ (2001) Advances in microbiotic soil crust research and its ecological significance in arid and semiarid regions. J Desert Res 21:4-11

Liu LC, An XQ, Li XR (2003) Characteristics of sand-dust storm in Yanchi county, Ningxia province. J Desert Res 23: 33-37

McMahon H (1906) Recent exploration and survey of Sistan. Geogr J 28:210-228

McTainsh GH (1998) Dust Storm Index. In: Sustainable agriculture: assessing Australia's recent performance. SCARM Tech Rep 70, CSIRO, Collingwood, p 65-72

McTainsh GH, Lynch AW, Burgess RC (1990) Wind erosion in eastern Australia. Aust J Soil Res 28:323-339

Pye K, Tsoar H (1991) Aeolian sand and sand dunes. Unwin Hyman, Boston, MA

Qiu XF, Zeng Y, Miao QL (2001) Temporal-spatial distribution as well as tracks and source areas of sanddust storms in China. Acta Geogr Sin 56:316-322

Reynolds JF, Stafford-Smith DM (eds) (2002) Global desertification: do humans cause deserts? Dahlem Workshop Report, Vol 88, Dahlem University Press, Berlin

Safarnejad A (2005) Comparison of saxaoul species (Haloxylon spp.) for its improvement and expansion in desert areas. J Res Constr Nat Res 67:51-57

Shi GY, Zhao SX (2003) Several scientific issues of studies on the dust storms. Chin J Atmos Sci 27:591-606

Shi PJ, Yan P, Gao SY (2000) Progress in sandstorm studies in China and perspectives. J Nat Disasters 9:71-77 (in Chinese)

Squires VR (1995) Desertification, climate change and the world's drylands. In: Alsharhan AS, Wood WW, Goudie A, Glennie KW, Abdellatif EM (eds) Desertification in the Third Millenium. Balkema, Rotterdam

Squires VR (2001) White sandstorms in Central Asia. In: Youlin Y, Squires VR, Lu Q (eds) Global alarm: dust and sand storms from the world's drylands. UNCCD, Bangkok, p 169-201

Tac Sabz Consultant Engineers (2002) Identification of critical regions of wind erosion and determination of executive priorities of Iran. Project Rep, Bureau of Sand Dune Fixation and Desertification Control. Forest, Rangeland and Watershed Organizations of Iran, Teheran

Tao JH, Wang JS, Feng JY (2004) Applying of helicity in analysis of a severe sandstorm. J Desert Res 24:83-87

- Tucker CJ, Dregne HE, Newcomb WW (1991) Expansion and contraction of the Sahara Desert from 1980 to 1990. Science 253:299-301

Vekerdy Z, Dost RJJ, Reinink G, Partow H (eds) (2006) History of environmental change in the Sistan Basin: based on 
satellite image analysis: 1976-2005. UN Environmental Programme, Geneva

Wang SG, Dong GR, Yang DB (1996) A study of sandstorm over the desert region in North China. J Nat Disasters 5:86-94

Wang $\mathrm{T}$ (2000) Land use and sandy desertification in the North China. J Desert Res 20:103-107

Wang T, Chen GT, Qian ZA, Yang GS, Qu JJ, Li DL (2001) Situation of sand-dust storms and countermeasures in north China. J Desert Res 21:322-327

WAPCOS (Water and Power Development Consultancy Services) (1975) Lower Helmand Valley development

Wiggs GFS, Thomas DSJ, Bullard JE (1995) Dune mobility and vegetation cover in the southwest Kalahari Desert. Earth Surf Process Landf 20:515-529

Xia XC, Yang GS (1996) Sandstorm disasters in northwest China and control. China Publishing House for Environ-

Editorial responsibility: Bryson Bates, Wembley, Australia mental Sciences, Beijing (in Chinese)

Zehtabian GR, Azarnivand H, Jafari M, Nazeri K, Esmaeelzaede H (2006) The effect of Haloxylon aphyllum and Calligonum commosum stabilization and rehabilitation of sand dune (case study: Reza-Abad, Semnan Province, Iran). J Desert Res 11:167-175

Zhang CL, Zou XY, Gong GR, Liu LY, Liu YZ (2004) Aerodynamic roughness of cultivated soil and its influence on soil erosion by wind in a wind tunnel. Soil Till Res 75:53-59

Zhang DE (1984) A climatological study of dust storms in Chinese history. Sci Chin Ser D 24:278-288 (in Chinese)

Zhang H, Li FR, Fu QK, Lu ZJ (2004) Field investigation on ecological effect of windbreak and soil erosion reduction from sandy grasslands. J Environ Sci 25:119-124 (in Chinese)

Zobeck TM (1991) Soil properties affecting wind erosion. J Soil Water Conserv 46:112-118

Submitted: March 19, 2009; Accepted: November 27, 2009 Proofs received from author(s): February 17, 2010 